\title{
The Role of Suppliers of Raw Materials in Ensuring Food Safety
}

\author{
Katarzyna Jakubowska Gawlik and Joanna Trafialek* \\ Warsaw University of Life Sciences, Poland
}

*Corresponding author: Joanna Trafialek, Faculty of Human Nutrition and Consumer Sciences, Warsaw University of Life Sciences, Poland.

Received Date: February 23, 2019

Published Date: April 17, 2019

\section{Food Safety}

Food safety is the most important quality feature for consumers, hence food law regulates this issue in details assuring food the consumer buys meets its safety expectations. According to the Codex Alimentarius Commission (CAC) [1], food safety is the assurance that food will not cause harm to the consumer when it is prepared and/or eaten according to its intended use. Food safety is very important for consumers and producers as well. All food producers are responsible for ensuring food safety. Therfore, they should pay attention to the quality of raw materials use in a production proces.

Suppliers play a significant role in food industry sectors. The quality of the final product is determined by many factors: one of the most important tools to ensure high quality of raw materials is suppliers qualifications list. Ensuring that incoming raw materials are free from hazards is the most effective way of keeping dangers away from the food and the manufacturing facility. An adopted approach to food safety should cover the entire supply chain, starting with suppliers. Selecting suppliers is one of the most important activities in supply chain management.

\section{Selecting Suppliers}

Each food plant should follow strict procurement processes to ensure selecting safe, high quality raw materials. This includes defining specifications for the materials, and performing checks to ensure they always comply with the regulations. If they don't comply, they should be rejected.

The choice of suppliers is a very important management process in food business requiring well-structured operational procedures. Generally, there are two methods of choosing suppliers: 1." single sourcing" - one supplier can meet all the needs of the purchaser and 2. "multiple sourcing" where in order to decrease the risk of non- availability of raw material, the purchaser buys raw materials from several suppliers [2]. Cooperating with correct suppliers decreases the costs and improves competitiveness [3] so purchasing strategy is a critical activity for each food company [4]. Choosing a supplier that can deliver a safe product should be the crucial objective of food plant.

\section{Methods for Assessing Suppliers}

There are few methods for selecting and monitoring suppliers. A good review of methods supporting supplier selection is represented by Aissaoui et.al [5] and Ho et.al [6]. Various methods to assess suppliers are presented in number of studies. For example, Ghodsypour and O'Brien [7] used the fuzzy analytic hierarchy process "FAHP" to choose the supplier, assessing the following criteria: costs, quality, supplier's profile and risk factors. Amid et al. [2] used the fuzzy goal programming "FGP" in order to set the appropriate quantity of orders placed with particular suppliers taking into account the lowest prices and the highest quality. Laeequddin et al. [8] developed a trust building model through risk evaluation in supply chain and data were analyzed using multiple regression analyses. However, the above-mentioned methods are not well known in food industry, neither are they very common in small and medium size companies in the European Union.

There is a lack of a simple method of assessing suppliers in food business. Trafiałek et al. [9] proposed a useful method of assessing the risk of negative effect of a given supplier on the quality and safety of finished food products. Risk assessment is based on six criteria for each supplier: the type of commodities or products provided by the supplier, the period of cooperation with the supplier, systems used by the supplier to guarantee food quality, safety and reliability of services, and past performance with respect to delayed deliveries, cancelled deliveries and deliveries against which complaints were 
filed due to insufficient quantity of raw materials. The method can be used in small companies and does not require complicated calculations or advanced statistical techniques. Thus, it could be very helpful for small businesses yet has same limitations, e.g. the knowledge and awareness of employees.

Therefore, for the smallest food business operators it is recommended to consider the following steps when selecting and keeping suppliers. The first one is determining what type of food safety systems a given supplier has in place. According to EU law, Good Hygienic Practice and HACCP system are mandatory. The second step is finding out whether they receive raw materials from selected and reliable sources. The next one is to conduct an inspection of the supplier's facility before starting cooperation with them. All suppliers have to meet hygienic requirements and it should be checked on place. This is especially important if they supply high-risk raw materials or if there are doubts about their food safety systems. It is recommended to inspect the supplier from time to time and find out what kind of food safety training the supplier provides to its employees. The condition of a supplier's delivery trucks and equipment must be examined on each delivery. To maintain an expected level of quality of a delivery, the products being supplied should be monitored to make sure that the supplier consistently provides the expected products. It is essential to monitor the cooperation effectively with a given supplier as well as the quality of the raw materials delivered.

Nowadays, there are numerous food standards and specifications to which food producer and entrepreneurs must refer, however, they rarely have the knowledge to assess the suppliers [10].

\section{Summary}

In the summery, the authors wont draw attention to proper cooperation with suppliers and the need for selecting them carefully. This is because it is substantial to guarantee safety of products and right quality of raw materials.

\section{Conflict of Interest}

\author{
No Conflict of Interest.
}

\section{Aknowledgement}

None.

\section{References}

1. Codex Alimentarius (2009) Food hygiene basic texts, (4 ${ }^{\text {th }}$ edn), WHO/ FAO, Rome, Italy.

2. Amid A, Ghodsypour SH, O Brien C (2006) Fuzzy multiobjective linear model for supplier selection in a supply chain. International Journal of Production Economics, 104(2): 394-407.

3. Meena PL, Sarmah SP, Sarkar A (2011) Sourcing decisions under risks of catastrophic event disruptions. Research Part E Logistics 47(6): 10581074.

4. Aissaoui N, Haouari M, Hassini E (2007) Supplier selection and order lotsizing modelling. A review. Computers and Operations Research 34(12): 3516-3540.

5. Costantino N, Pellegrino R (2010) Choosing between single and multiple sourcing based on supplier default risk: a real options approach. Journal of Purchasing and Supply Management 16(1): 27-40.

6. Ho W, Xu X, Dey P K (2010) Multi-criteria decision making approaches for supplier evaluation and selection: A literature review. European. Journal of Operational Research 202(1): 16-24.

7. Ghodsypour SH, O Brien C (1998) A decision support system for supplier selection using an integrated analytic hierarchy process and linear programming. International Journal of Production Economics 56-57(1): 199-212.

8. Laeequddin M, Sardana GD, Sahay BS, Waheed KA, Sahay V (2009) Supply chain partners trust building through risk evaluation: the perspectives of UAE packaged food industry. Supply Chain Management 14(4): 28090 .

9. Trafiałek J, Lücke FK, Kołożyn Krajewska D, Bilska B, Tomaszewska M, et al. (2017) Assessment of suppliers in food business: is there a way to estimate the risk? Food. Science. Technology. Quality. 24 (1): 139-154.

10. Wallace C,Carol Wallace (Author) , Visit Amazon's Carol Wallace PageFind all the books, read about the author, and more.See Are you an author? Sperber W, Mortimore SE (2011) Food Safety for the $21^{\text {st }}$ Century: Managing HACCP and Food Safety throughout the Global Supply Chain. Willey - Blackwell, UK. 